\title{
Changes in renal function increase the need for advanced ventilatory support and increase the risk of mortality in critically ill patients with COVID-19
}

\author{
NICKSON MELO DE MORAIS ${ }^{1}$, LARA CANDICE COSTA DE MORAIS LEONE ${ }^{2}$, \\ VALÉRIA DUARTE DE ALMEIDA ${ }^{1}$, MICÁSSIO FERNANDES DE ANDRADE ${ }^{2}$, \\ ELLANY GURGEL COSME DO NASCIMENTOO ${ }^{2,3}$, JOSÉ VERÍSSIMO FERNANDES ${ }^{4}$, \\ CHRISTIANE MEDEIROS BEZERRA ${ }^{4}$ and THALES ALLYRIO ARAÚJO DE MEDEIROS FERNANDEZ ${ }^{1-3}$ \\ ${ }^{1}$ Multicentric Postgraduate Program in Physiological Sciences, ${ }^{2}$ Department of Biomedical Sciences and \\ ${ }^{3}$ Postgraduate Program in Health and Society, University of Rio Grande do Norte State, Mossoró, Rio Grande do Norte 59607-360; \\ ${ }^{4}$ Department of Microbiology and Parasitology, Federal University of Rio Grande do Norte, \\ Natal, Rio Grande do Norte 59078-970, Brazil
}

Received September 4, 2021; Accepted December 17, 2021

DOI: $10.3892 / b r .2022 .1501$

\begin{abstract}
In addition to respiratory failure, another important outcome presented by patients hospitalized with coronavirus disease 2019 (COVID-19) is renal failure, which is related to increased severity of infection and a greater risk of mortality. Severity is often represented by the need for respiratory and/or life support, which can range from oxygen therapy to invasive mechanical ventilation. This study aimed to determine the association between the degree of renal and inflammatory impairment in patients with the need for advanced respiratory support and mortality. Included in the present study were 79 critically ill patients with COVID-19 on different days, who required a nasal cannula and/or orotracheal intubation. Data from laboratory tests, arterial blood gases and information on their clinical evolution were collected. The results obtained showed that the biochemical markers of renal function, as well as the inflammatory markers and the partial pressure of carbon dioxide, were significantly increased in patients who succumbed to the infection. Similarly, these markers were higher amongst patients who required increased respiratory assistance.
\end{abstract}

\section{Introduction}

The etiological agent of the new coronavirus disease is the SARS-CoV-2 virus, which has a high affinity for the

Correspondence to: Mr. Nickson Melo de Morais, Multicentric Postgraduate Program in Physiological Sciences, University of Rio Grande do Norte State, Atirador Miguel Antônio da Silva Neto Street, Mossoró, Rio Grande do Norte 59607-360, Brazil

E-mail: nicksonmm@yahoo.com.br

Key words: coronavirus disease 2019, SARS-CoV-2, respiratory therapy, airway management, kidney function tests, acute kidney injury, inflammatory mediators angiotensin-2 converting enzyme (ACE2). Since this protein is abundantly expressed in the pulmonary epithelium, it facilitates colonization of the respiratory system, which is the primary system affected by the disease (1).

In addition to respiratory failure, $30 \%$ of hospitalized patients experience renal failure that usually occurs 7 to 14 days after admission. This involvement is related to a greater severity of infection, and an increased risk of mortality (2). Severity is often represented by the degree of respiratory and life support required, which can range from oxygen therapy through a nasal cannula and non-rebreather mask, to invasive mechanical ventilation, such as orotracheal intubation and tracheostomy (3). The involvement of these systems comes from direct and indirect injuries that generate a local inflammatory response, in addition to the cytokine storm that will have already occurred in critically ill patients affected by the disease (4).

To the best of our knowledge, there are no studies that have assessed the association between the biochemical parameters of renal function and the need for respiratory support and risk of mortality in patients with severe COVID. Therefore, this study aims to relate the degree of renal and inflammatory impairment with mortality, and the increased need for respiratory support.

\section{Patients and methods}

Ethical considerations. The Human Research Ethics Committee of Rio Grande do Norte State University, (Mossoró Brazil), approved the study protocol (approval no. CAAE: 36510420.6.0000.5294).

Study population. Medical records of severe COVID-19 patients were analyzed. All of the patients had a confirmed diagnosis of the viral infection by reverse transcription-PCR, and had been admitted to the Intensive Care Unit of Hospital Regional Tarcisio de Vasconcelos Maia (Mossoró, Brazil) between April and December 2020. 
Inclusion and exclusion criteria. The present study was an observational and cross-sectional study. A total of 79 severe COVID-19 patients were included (median age, 60.5 years; age range, 18-100; female/male, 25/54). The study included patients on the second day of nasal cannula use, on the second day after orotracheal intubation, and the eighth day after intubation, as these represent notably different instances of care. Patients in the prone position on the day of analysis and patients under the age of 18 years were excluded.

Data collection. Information from patients' medical records were collected. Data from laboratory tests [hemogram, alanine transferase (ALT), aspartate transferase (AST), urea, creatinine, lactic dehydrogenase ( $\mathrm{LDH}$ ), and quantitative $\mathrm{C}$-reactive protein (CRP)], arterial blood gases [partial pressure of oxygen $\left(\mathrm{PaO}_{2}\right)$ and $\left.\mathrm{CO}_{2}(\mathrm{PaCO} 2)\right]$, as well as information on clinical evolution were all obtained. For evaluation purposes, the traditional reference values of the analyzed biomarkers were considered (5-8).

A leukogram was performed using a semi-automated method (9) on a BS-3000 Plus (Mindray); ALT, AST, urea, creatinine and $\mathrm{LDH}$ levels were measured using the Kinetic method (10) on a BS-380 (Mindray), and the CRP levels were determined using the Latex Agglutination method on Titertek Multiskan (MCC Flow Labs Inc.) (11). Arterial blood gases were measured using Stat Profile Prime ${ }^{\circledR}$ (Novo Biomedical).

To determine whether patients exhibited acute kidney injure (AKI), the following diagnostic criteria were used: Creatinine levels, $\geq 0.3 \mathrm{mg} / \mathrm{dl}(>26.5 \mu \mathrm{mol} / \mathrm{l})$ observed within $48 \mathrm{~h}$, an increase in creatinine to $\geq 1.5$ times baseline, which is known or presumed to have occurred within the prior 7 days or a urine volume $<0.5 \mathrm{ml} / \mathrm{kg} / \mathrm{h}$ for $6 \mathrm{~h}$ (12).

To consider acute kidney failure, the following diagnostic criteria were used: A threefold increase in serum creatinine levels or levels $\geq 350 \mu \mathrm{mol} / 1$ with an acute rise of $44 \mu \mathrm{mol} / \mathrm{l}$, a decrease in glomerular filtration $>75 \%$, a urine output $<0.5 \mathrm{ml} / \mathrm{kg} / \mathrm{h}$ for over $24 \mathrm{~h}$ or anuria for over $12 \mathrm{~h} \mathrm{(13).}$

For evaluation purposes, two distinct aspects were considered in the patients: Mortality in the ICU (death and discharge outcomes), and the need for respiratory assistance (use of nasal cannula and/or invasive mechanical ventilation, the latter covering both patients on the second day of intubation and those on the eighth day).

Statistical analysis. To determine the distribution of the variables, a Kolmogorov-Smirnov test was performed, analyzing the asymmetry and kurtosis, which ideally should be between- 2 and +2 , the Gaussian curve shape, and the similarity between the mean and the median. For comparison of the data, the data were assessed based on two factors: mortality vs. discharge, and the need for use of a nasal catheter or invasive mechanical ventilation. Normally distributed data were compared using an independent samples t-test and data showing a skewed distribution were compared using the non-parametric Mann-Whitney U test. Data analyzed using a Student's t-test is presented as the mean \pm SD or SEM, and data analyzed using a Mann-Whitney $U$ test is presented as the median (IQR). $\mathrm{P}<0.05$ was considered to indicate a statistically significant difference.

\section{Results}

A total of 79 critically ill patients affected by COVID-19 were evaluated: 29 Patients on the 2 nd day of nasal oxygen cannula use, 37 on the 2 nd day after orotracheal intubation, and 13 on the 8th day after intubation. There were 25 female patients $(31.6 \%$; median age, 64.0 years; age range, $18-90$ years) and 54 male (68.4\%; median age, 59.0 years; age range, 23-100 years), with a combined median age of 60.5 years and a combined age range of 18-100. The mean stay in the ICU was 13.3 days, where 35 patients were discharged (44\%) and 44 succumbed to the disease $(56 \%)$. The most-reported commonly comorbidity amongst patients was Systemic Arterial Hypertension (55\%). A total of $79.5 \%$ of patients used vasoactive drugs, and $77 \%$ used sedative drugs. Of the cohort, 16 patients (20\%) required hemodialysis.

The biochemical markers of renal function (urea and creatinine), as well as the inflammatory markers (CRP, LDH and leukocyte counts), and the $\mathrm{PaCO}_{2}$ were significantly increased in patients who succumbed to the disease (Table I). Similarly, these markers (except for LDH) were also higher amongst patients who required more invasive respiratory assistance (Table II).

\section{Discussion}

The results of the present study showed that urea, creatinine, $\mathrm{CRP}$, leukocyte counts and $\mathrm{PaCO}_{2}$ were increased in patients who required increased respiratory assistance as well as in those who died. Lack of more sensitive blood markers, such as N-Gal, cystatin-C and retinol-binding protein was a limitation of this study, but markers most used in Intensive Care Units were assessed, and thus the results provided are more clinically relevant.

Once the virus binds to the ACE2 receptor, the body will fight the invading microorganism, generating a cytokine storm in the process (14). The cytokine storm is a potentially life-threatening systemic inflammatory syndrome involving elevated levels of circulating cytokines and immune-cell hyperactivation. In short, a cytokine storm involves an immune response that causes collateral damage, which may be greater than the immediate benefit of the immune response (15). However, when the inflammatory response is uncompensated, the amount of blood that would normally be directed to the glomeruli is below the normal level. Blood retention can trigger another problem: The formation of a thrombus, which is the indirect means by which SARS-CoV-2 reaches the kidneys $(14,16)$.

Acute lung injury and AKI are complications frequently encountered in critically ill patients. Damage to the lung and/or kidneys occurs in clinical situations similar to that observed during systemic inflammatory response syndrome, shock and in the evolution of multiple organ dysfunction (17). The cytokine storm and the direct lesions present in COVID-19 generate these lesions, and the complications appear simultaneously, and a patient with renal failure is more likely to need more advanced ventilatory support (18).

Regarding kidney injury and death, there is a significantly higher in-hospital mortality rate in patients with kidney abnormalities, including elevated baseline serum creatinine, proteinuria and hematuria levels, as well as acute kidney failure (16). In addition, patients with elevated baseline serum creatinine levels have higher white blood cell counts and lower lymphocyte and platelet counts (19). 
Table I. Comparison of laboratory and blood gas data in accordance with the clinical outcomes.

\begin{tabular}{|c|c|c|c|}
\hline \multirow[b]{2}{*}{ Analyzed parameter (Reference value) } & \multicolumn{2}{|c|}{ Clinical outcome } & \multirow[b]{2}{*}{ P-value } \\
\hline & $\begin{array}{l}\text { Death, } \mathrm{n}=44, \text { median, } \\
\mathrm{IQR} / \text { mean } \pm \mathrm{SD}\end{array}$ & $\begin{array}{c}\text { Discharged, } \mathrm{n}=35, \\
\text { median, } \mathrm{IQR} / \text { mean } \pm \mathrm{SD}\end{array}$ & \\
\hline \multicolumn{4}{|l|}{ Kidney function } \\
\hline Creatinine (0.7-1.2 mg/dl) & $1.33,1.81^{\mathrm{d}}$ & $0.80,0.5^{\mathrm{d}}$ & $0.002^{\mathrm{c}}$ \\
\hline Urea $(15-45 \mathrm{mg} / \mathrm{dl})$ & $88.00,97^{\mathrm{d}}$ & $54.00,37^{\mathrm{d}}$ & $0.003^{\mathrm{c}}$ \\
\hline \multicolumn{4}{|l|}{ Liver function } \\
\hline Aspartate transferase (12-46 U/1) & $57.00,43^{\mathrm{d}}$ & $42.00,34^{\mathrm{d}}$ & 0.105 \\
\hline Alanine transferase (3-50 U/1) & $37.00,26^{\mathrm{d}}$ & $44.00,49^{\mathrm{d}}$ & 0.082 \\
\hline \multicolumn{4}{|l|}{ Gasometric data } \\
\hline $\mathrm{PaO}_{2}(60-100 \mathrm{mmHg})$ & $79.00,36.2^{\mathrm{d}}$ & $72.10,28.07^{\mathrm{d}}$ & 0.339 \\
\hline $\mathrm{PaCO}_{2}(35-45 \mathrm{mmHg})$ & $51.84 \pm 18.94^{\mathrm{e}}$ & $38.46 \pm 12.04^{\mathrm{e}}$ & $0.001^{\mathrm{c}}$ \\
\hline \multicolumn{4}{|l|}{ Inflammatory markers } \\
\hline Lactate dehydrogenase (230-460 U/1) & $1,077.91 \pm 367.20^{\mathrm{e}}$ & $929.20 \pm 388.44^{\mathrm{e}}$ & $0.035^{\mathrm{a}}$ \\
\hline C-reactive protein $(<6 \mathrm{mg} / \mathrm{l})$ & $95.19 \pm 44.07^{\mathrm{e}}$ & $72.95 \pm 44.2^{\mathrm{e}}$ & $0.006^{\mathrm{b}}$ \\
\hline Lymphocyte $(21-35 \%)$ & $12.00,7.00^{\mathrm{d}}$ & $10.00,9.00^{\mathrm{d}}$ & 0.768 \\
\hline Leukocytes $\left(5,000-10,000 / \mathrm{mm}^{3}\right)$ & $12,700.00,8,500^{\mathrm{d}}$ & $11,050.00,5,700^{\mathrm{d}}$ & $0.026^{\mathrm{a}}$ \\
\hline Platelet/lymphocyte $(\leq 2.98)$ & $140.87,134.40^{\mathrm{d}}$ & $184.83,213.25^{\mathrm{d}}$ & 0.070 \\
\hline Neutrophils/lymphocytes $(\leq 6.63)$ & $8.71,5.21^{\mathrm{d}}$ & $9.54,6.78^{\mathrm{d}}$ & 0.756 \\
\hline
\end{tabular}

${ }^{\mathrm{a} P} \leq 0.05,{ }^{\mathrm{b}} \mathrm{P} \leq 0.01,{ }^{\mathrm{c}} \mathrm{P} \leq 0.001 .{ }^{\mathrm{d}}$ Median, IQR, compared using a Mann-Whitney U test; ${ }^{\mathrm{e}} \mathrm{Mean} \pm \mathrm{SD}$, compared using an unpaired Student's t-test.; $\mathrm{Pa}$, partial pressure.

Table II. Comparison of laboratory and blood gas data in accordance with the need for respiratory support.

\begin{tabular}{|c|c|c|c|}
\hline \multirow[b]{2}{*}{ Analyzed parameter (Reference value) } & \multicolumn{2}{|c|}{ Respiratory support } & \multirow[b]{2}{*}{ P-value } \\
\hline & $\begin{array}{l}\text { Mechanical ventilation, } \mathrm{n}=50 \\
\text { median, } \mathrm{IQR} / \text { mean } \pm \mathrm{SD}^{\mathrm{e}}\end{array}$ & $\begin{array}{c}\text { Nasal cannula, } \mathrm{n}=29, \\
\text { median }^{\mathrm{d}} / \mathrm{mean}^{\mathrm{e}} ; \mathrm{IQR}^{\mathrm{d}} / \pm \mathrm{SD}^{\mathrm{e}}\end{array}$ & \\
\hline \multicolumn{4}{|l|}{ Kidney function } \\
\hline Creatinine $(0.7-1.2 \mathrm{mg} / \mathrm{dl})$ & $1.27,1.7^{\mathrm{d}}$ & $0.79,0.39^{\mathrm{d}}$ & $0.006^{\mathrm{c}}$ \\
\hline Urea $(15-45$ mg/dl) & $82.00,103.00^{\mathrm{d}}$ & $62.00,41.00^{\mathrm{d}}$ & $0.024^{\mathrm{a}}$ \\
\hline \multicolumn{4}{|l|}{ Liver function } \\
\hline Aspartate transferase (12-46 U/l) & $43.00,45.00^{\mathrm{d}}$ & $57.00,24^{\mathrm{d}}$ & 0.664 \\
\hline Alanine transferase $(3-50 \mathrm{U} / \mathrm{l})$ & $37.00,34.00^{\mathrm{d}}$ & $43.00,38^{\mathrm{d}}$ & 0.214 \\
\hline \multicolumn{4}{|l|}{ Gasometric data } \\
\hline $\mathrm{PaO}_{2}(60-100 \mathrm{mmHg})$ & $74.50,30.4^{\mathrm{d}}$ & $71.75,41.25^{\mathrm{d}}$ & 0.580 \\
\hline $\mathrm{PaCO}_{2}(35-45 \mathrm{mmHg})$ & $52.16 \pm 17.05^{\mathrm{e}}$ & $31.76 \pm 7.66$ & $0.000^{\mathrm{c}}$ \\
\hline \multicolumn{4}{|l|}{ Inflammatory markers } \\
\hline LDH (230-460 U/1) & $1,010.68 \pm 420.00^{\mathrm{e}}$ & $981.82 \pm 311.02^{\mathrm{e}}$ & 0.415 \\
\hline C-reactive protein $(<6 \mathrm{mg} / \mathrm{l})$ & $94.49 \pm 45.32^{\mathrm{e}}$ & $63.77 \pm 38.38^{\mathrm{e}}$ & $0.004^{\mathrm{b}}$ \\
\hline Lymphocyte $(21-35 \%)$ & $10.50,7^{\mathrm{d}}$ & $14.50,10.5^{\mathrm{d}}$ & 0.120 \\
\hline Leukocytes $\left(5,000-10,000 / \mathrm{mm}^{3}\right)$ & $12,850.00,5,650.00^{\mathrm{d}}$ & $9,600.00,7,125.00^{\mathrm{d}}$ & $0.013^{\mathrm{a}}$ \\
\hline Platelet/lymphocyte $(\leq 2.98)$ & $141.71,131.90^{\mathrm{d}}$ & $186.35,152.13^{\mathrm{d}}$ & 0.162 \\
\hline Neutrophils/lymphocytes $(\leq 6.63)$ & $9.54,5.84^{\mathrm{d}}$ & $6.90,5.63^{\mathrm{d}}$ & 0.117 \\
\hline
\end{tabular}

${ }^{\mathrm{a} P} \leq 0.05,{ }^{\mathrm{b}} \mathrm{P} \leq 0.01,{ }^{\mathrm{c}} \mathrm{P} \leq 0.001 .{ }^{\mathrm{d}}$ Median, IQR, compared using a Mann-Whitney U test; ${ }^{\mathrm{e}} \mathrm{Mean} \pm \mathrm{SD}$, compared using an unpaired Student's t-test.; $\mathrm{Pa}$, partial pressure. 
The incidence of AKI is significantly higher in patients with elevated baseline serum creatinine levels than in patients with normal baseline values (19). The mentioned alterations contribute to a worse prognosis and higher mortality in patients with AKI, showing the relationship between kidney damage and disease severity (20).

Other factors that may contribute to the worsening of renal function are pre-existing diseases, such as systemic arterial hypertension and diabetes mellitus, which lead to renal vascular injury and consequent lesions. Cardiovascular changes also contribute to the patient's course of respiratory failure, the need for mechanical ventilation and the development of renal complications due to low perfusion in other organs and the use of nephrotoxic drugs (16).

In conclusion, patients who are at greater risk of AKI may require more intensive care, as they present with an increased need for ventilatory support and increased risk of mortality in the ICU. COVID-19 is a complex disease that requires attention and treatment of several bodily systems, in addition to the respiratory system.

\section{Acknowledgements}

We are thankful to the Hospital Regional Tarcísio Maia for their availability and to the patients and family members who were willing to participate in this research.

\section{Funding}

This research was funded in part by Coordenação de Aperfeiçoamento de Pessoal de Nível Superior-Brazil (CAPES) (grant no. 001).

\section{Availability of data and materials}

The datasets generated and/or analyzed during the present study are not publicly available due to privacy requirements of the inpatients data, but are available from the corresponding author on reasonable request.

\section{Authors' contributions}

NMDM was involved in the conception of the study, data acquisition and analysis, and drafting of the manuscript. LCCDML, VDDA and MFDA were involved in data acquisition and analysis, and drafting the manuscript. EGCDN, JVF, CMB and TAADMF analyzed and interpretated the data. All authors read and approved the final manuscript. NMDM and VDDA confirm the authenticity of all the raw data.

\section{Ethics approval and consent to participate}

The study protocol was analyzed and approved by the Human Research Ethics Committee from Rio Grande do Norte State University (Mossoró, Brazil; approval no. CAAE: 36510420.6.0000.5294).

\section{Patient consent for publication}

Not applicable.

\section{Competing interests}

The authors declare that they have no competing interests.

\section{References}

1. Yuki K, Fujiogi M and Koutsogiannaki S: COVID-19 pathophysiology: A review. Clin Immunol 215: 108427, 2020.

2. Cheng Y, Luo R, Wang K, Zhang M, Wang Z, Dong L, Li J, Yao Y, $\mathrm{Ge} \mathrm{S}$ and $\mathrm{Xu}$ G: Kidney disease is associated with in-hospital death of patients with COVID-19. Kidney Int 9: 829-838, 2020.

3. Nicholson TW, Talbot NP, Nickol A, Chadwick AJ and Lawton O: Respiratory failure and non-invasive respiratory support during the covid-19 pandemic: An update for re-deployed hospital doctors and primary care physicians. BMJ 369: m2446, 2020.

4. Iwasaki A and Pillai PS: Innate immunity to influenza virus infection. Nat Rev Immunol 14: 315-328, 2014.

5. Rosenfeld LG, Malta DC, Szwarcwald CL, Bacal NS, Cuder MA, Pereira CA Figueiredo AW, Silva AG, Machado ÍE, Silva WA, et al: Reference values for blood count laboratory tests in the Brazilian adult population, National Health Survey. Rev Bras Epidemiol 22 (Suppl 2): E190003.SUPL.2, 2019 (In Portuguese, English).

6. Malta DC, Machado IE, Pereira CA, Figueiredo AW, Aguiar LK, Almeida WS Maria de Fatima Marinho de S, Gastão RL and Landman CS: Avaliação da função renal na população adulta brasileira, segundo critérios laboratoriais da Pesquisa Nacional de Saúde. Rev Bras Epidemiol 22: E190010, 2019.

7. López-Escobar A, Madurga R, Castellano JM, Ruiz de Aguiar S, Velázquez S, Bucar M, Jimeno S and Ventura PS: Hemogram as marker of in-hospital mortality in COVID-19. J Investig Med 69: 962-969, 2021.

8. Li X, Liu C, Mao Z, Xiao M, Wang L, Qi S and Zhou F: Predictive values of neutrophil-to-lymphocyte ratio on disease severity and mortality in COVID-19 patients: A systematic review and meta-analysis. Crit Care 24: 647, 2020.

9. Van Dyke TE, Reilly AA, Horoszewicz H, Gagliardi N and Genco RJ: A rapid, semi-automated procedure for the evaluation of leukocyte locomotion in the micropore filter assay. J Immunol Methods 31: 271-282, 1979.

10. Lustgarten JA and Wenk RE: Simple, rapid, kinetic method for serum creatinine measurement. Clin Chem 18: 1419-1422, 1972.

11. Collet-Cassart D, Van den Abbeele E and Poncelet S: A quantitative C-reactive protein assay using latex agglutination in microtiter plates. J Immunol Methods 125: 137-141, 1989.

12. Kellum JA: Diagnostic Criteria for Acute Kidney Injury: Present and Future. Crit Care Clin 31: 621-632, 2015.

13. Bellomo R, Ronco C, Kellum JA, Mehta RL and Palevsky P; Acute Dialysis Quality Initiative workgroup: Acute renal failure-definition, outcome measures, animal models, fluid therapy and information technology needs: The Second International Consensus Conference of the Acute Dialysis Quality Initiative (ADQI) Group. Crit Care 8: R204-R212, 2004.

14. Kunutsor SK and Laukkanen JA: Renal complications in COVID-19: A systematic review and meta-analysis. Ann Med 52: 345-353, 2020.

15. Fajgenbaum DC and June CH: Cytokime Storm. N Engl J Med 383: 2255-2273, 2020.

16. Gabarre P, Dumas G, Dupont T, Darmon M, Azoulay E and Zafrani L: Acute kidney injury in critically ill patients with COVID19. Intensive Care Med 46: 1339-1348, 2020.

17. Grasselli G, Greco M, Zanella A, Albano G, Antonelli M, Bellani G, Bonanomi E, Cabrini L, Carlesso E, Castelli G, et al: Risk factors associated with mortality among patients with COVID-19 in intensive care units in Lombardy, Italy. JAMA Intern Med 180: 1345-1355, 2020.

18. Koyner JL and Murray PT: Mechanical ventilation and the kidney. Blood Purif 29: 52-68, 2010.

19. Pio-Abreu A, Nascimento MM, Vieira MA, Menezes Neves PD, Lugon JR and Sesso R: High mortality of CKD patients on hemodialysis with Covid-19 in Brazil. J Nephrol 33: 875-877, 2020.

20. Dessie ZG and Zewotir T: Mortality-related risk factors of COVID-19: A systematic review and meta-analysis of 42 studies and 423,117 patients. BMC Infect Dis 21: 855, 2021. 